\title{
Well pattern and space deployment of horizontal well to prevent fracturing channeling in fractured reservoir
}

\author{
Jianming GUO ${ }^{1, a^{*}}$, Hongwei XIE ${ }^{1,}$,, Gang WANG ${ }^{1, a}$, Yan DANG ${ }^{1, a}$, Yanxia $\mathrm{Ll}^{2, \mathrm{~b}}$ \\ ${ }^{1}$ School of Petroleum Engineering, Xi'an Shiyou University, Shaanxi xi'an, 710065, China. \\ ${ }^{2}$ School of Earth Sciences \& Engineering, Xi'an Shiyou University, Shaanxi xi'an, 710065, China. \\ aemail: jmguo@xsyu.edu.cn, bemail: lyx4164@xsyu.edu.cn
}

Keywords: Well Pattern And Space; Fractured Reservoir; Horizontal Well; Fracturing Channeling Prevention

\begin{abstract}
The oil development of the Triassic Yanchang Formation Chang8 section of the fractured reservoir in the south of Ordos Basin Tianhuan Syncline has used horizontal determinant deployment well pattern. It is common for fracturing wells communicate with neighbouring wells, and leads to substantial decline in production capacity in the area. In this paper, apply related theory and statistical methods, qualitatively and quantitatively determine and describe the geological characteristics between wells. Then analyze the relationship between well pattern and well space and fracturing channeling, simulating the relationship between well space and capacity, determine the optimal well space. Finally, a scheme of well pattern and well space deployment for prevention fracturing channeling in fractured reservoir is proposed.
\end{abstract}

\section{Introduction}

In the process of horizontal well fracturing, the formation between the fractured wells and adjacent horizontal wells is directly connected with the artificial fractures. This phenomenon is called as horizontal well fracturing channeling. The connected well is described as fracturing channeling well. There are mainly two kinds of characteristics of horizontal wells fracturing channeling. Firstly, liquid production and water cut of fracturing channeling well increase suddenly. The water cut continues to increase, even as high as $100 \%$; secondly, the output of these wells decreased significantly[1].

The reasons of the horizontal well fracturing channeling are in many aspects of geology and engineering. Faults, fracture zone and natural fractures are the geological objective reasons. Well pattern and well space, well completion, the types of fracture and parameters, pump injection programs and scale are engineering factors. This paper mainly discusses the factors of well pattern and well space in the same condition of other engineering factors, which is one of the most direct factors of horizontal well fracturing channeling. It not only considers the inter-well distance, but also the relationship between the location of each well group and the relationship between the reservoir geological characteristics[2].

\section{Relationship between well space and fracturing channeling}

In the Honghe oilfield, with the rapid expansion of the scale of production, the number of horizontal wells and well pattern density are increasing. Horizontal inter-wells distance is between $300 \sim 550 \mathrm{~m}$ and average well space is about $420 \mathrm{~m}$; multi stage fracturing staged number average about 10 sections for a well. The phenomenon of horizontal well fracturing adjacent wells is gradually increasing. The maximum principal stress direction is $75^{\circ}$ and majority horizontal section of horizontal wells parallel to the minimum horizontal principal stress direction $\left(165^{\circ}\right)$ in the oilfield. A small part of the horizontal section is deviated from the direction of minimum horizontal principal stress with small angle[3].

Taking HH37 well area as an example, the development layer is Chang8 layer, the Chang8 ${ }_{1}^{2}$ of well area is narrow long sand body distribution, most wells are located on the sand thickness 
$8 \sim 18 \mathrm{~m}[4]$. There are 104 well groups in well area, as shown in table1. The minimum interwell distance in the table1 means the distance between the two wells in any direction.

Table1. Statistics of the number of fracturing channeling wells in different well space

\begin{tabular}{ccccccccc}
\hline & \multicolumn{3}{c}{ The total of well groups 104 } & \multicolumn{5}{c}{ Except dislocated well group 62 } \\
\cline { 2 - 9 } $\begin{array}{c}\text { Minimum well } \\
\text { distance, } m\end{array}$ & $\begin{array}{c}\text { Number } \\
\text { of } \\
\text { fractured } \\
\text { wells }\end{array}$ & $\begin{array}{c}\text { Number of } \\
\text { fracturing } \\
\text { channeling } \\
\text { wells }\end{array}$ & $\begin{array}{c}\text { Number of } \\
\text { wells without } \\
\text { fracturing } \\
\text { channeling }\end{array}$ & $\begin{array}{c}\text { Fracturing } \\
\text { channeling } \\
\text { rate, \% }\end{array}$ & $\begin{array}{c}\text { Number } \\
\text { of } \\
\text { fractured } \\
\text { wells }\end{array}$ & $\begin{array}{c}\text { Number of } \\
\text { fracturing } \\
\text { channeling } \\
\text { wells }\end{array}$ & $\begin{array}{c}\text { Number of } \\
\text { wells } \\
\text { without } \\
\text { fracturing } \\
\text { channeling }\end{array}$ & $\begin{array}{c}\text { Fracturing } \\
\text { channeling } \\
\text { rate, } \%\end{array}$ \\
\hline $0-100$ & 5 & 1 & 4 & 20 & 1 & 1 & 0 & 100 \\
$100-200$ & 9 & 1 & 8 & 11.11 & 2 & 1 & 1 & 50 \\
$200-300$ & 13 & 2 & 11 & 15.38 & 8 & 2 & 6 & 25 \\
$300-400$ & 39 & 12 & 27 & 30.77 & 28 & 12 & 16 & 42.86 \\
$400-500$ & 21 & 5 & 16 & 23.81 & 15 & 6 & 9 & 40 \\
$500-600$ & 12 & 5 & 7 & 41.67 & 6 & 4 & 2 & 66.67 \\
$600-700$ & 4 & 2 & 2 & 50 & 2 & 2 & 0 & 100 \\
$800-$ & 1 & 0 & 0 & 0 & 0 & 0 & 0 & 0 \\
summation & 104 & 28 & 75 & 27.18 & 62 & 28 & 34 & 27.18 \\
\hline
\end{tabular}

Statistics show: (1) the maximum well space of horizontal wells fracturing channeling in the well area is $644 \mathrm{~m}$. It means that if the well space is greater than $644 \mathrm{~m}$, there is no fracturing channeling phenomenon. But if the well space is less than $644 \mathrm{~m}$, not all wells are fractured channeling. Fracturing channeling rate change incompletely along with well space vary, fracturing channeling rate is the highest when well space between $600-700 \mathrm{~m}$. (2) the "dislocation well groups" refers to horizontal section of adjacent well groups never intersect along with maximum principal stress direction. Removing the "dislocation" well groups and only considering these well groups which follow the extension of maximum horizontal principal stress direction, there is no tendency to decrease the fracturing channeling along with the increasing well space. It indicates that fracturing channeling is caused by other factors in addition to the well space. Therefore, the well space is not the only or the main factor to control the fracturing channeling.

\section{Relationship between well pattern and fracturing channeling}

Through analyzing the geological characteristics of horizontal well fracturing channeling in the Honghe oilfield, it shows that main geologic factors of fracturing channeling are faults, fracture zones and fractures. Outcrop, core, seismic, logging and mud logging data explain the distribution of the fracture, fault, fracture zone and ground stress from different aspects of the study area. The relative relationship between the two can be directly observed by mapping the distribution of the existing well pattern and the geological features of the reservoir. The study shows that the reservoir geology master control features of fracturing channeling mainly include fault, fracture zone, fracture, ground stress and positional relationship with horizontal well.

\subsection{Analysis of position relationship of well groups}

The method of exhaustion statistical analysis is used in the paper. According to the well position of 71 horizontal wells in the HH37 well area, the fracturing channeling well groups likely to happen are up to 104. Well groups can be divided into three categories according to relative position. That is full inclusive, local inclusive and dislocation. statistics of well groups bearing fracturing channeling with three different position relationship show that the number of well groups with full inclusive are 24 and fracturing channeling rate is 62.5\%; local inclusive are 38 and fracturing channeling rate is $34.21 \%$. In 104 well groups, a total of 42 well groups dislocate and account for $40.38 \%$. The well space of these 42 well groups is between $67.98 \mathrm{~m}$ and $643.61 \mathrm{~m}$. What regardless of interwell reservoir geology characteristics, there is no phenomenon of fracturing channeling. As shown in table1, removing the 42 well groups which can't be fractured channeling, in the remaining 62 wells groups, it has the highest fracturing channeling rate, up to $66.67 \%$ when the well space between 500-600m[5]. 
The study shows that the maximum horizontal principal stress in the study area has absolutely control on the distribution and extension direction of fractured fracture. Well groups dislocation and adjacent wells can effectively avoid the artificial fracture of the fractured wells, so as to avoid adjacent wells to be pressured channeling; removing dislocated well groups, the well groups reduce from 104 to 62 groups; dislocation of well groups can effectively prevent pressure channeling, it provides basis for the optimization of the future well pattern and well space.

3.2. Analysis of geological characteristics of inter-well reservoir

According to the different geological characteristics of the reservoir, the area can be divided into 12 categories, there are 23 wells in collusion with the adjacent wells when fracturing, the fracturing channeling wells are up to 36 , a total of 62 pairs of wells.

According to the analysis of relationship between reservoir geological types and fracturing channeling in well groups. In summary, it can be seen that: (1) the fracturing channeling well occur in the four types of reservoir geological feature, type 11, type 12, type 7 and type 3, the fracturing channeling rate of the well area respectively is $77 \%, 73 \%, 60 \%, 40 \%$. The more concentrated, narrow and longer fault, fracture zone and fractures are, as a pipeline of pipe wall without leakage connect to the two wells, the more likely to cause fracturing channeling. Geological feature type of the reservoir is "integral fracture zone connected", only 6 pairs of well groups are no fracturing channeling, indicating that despite the fractured zone connects the two wells. As connectivity is excellent, the fracturing fluid is possible along the master made fracture stretch in a vertical direction. Therefore, it is not easy to be fractured channeling. Similarly, it is difficult to be fractured channeling in the place where fracture is not developed. (2) The effect of ground stress is another main factor of fracturing channeling, which controls the stretch direction of the fractured fracture. The distribution direction of horizontal wells in study area is very uniform. The orientation of horizontal section is basically limited in between $165^{\circ}$ and $285^{\circ}$, it coincided with the the maximum horizontal principal stress direction in study area at an angle of $90^{\circ}$, namely well seam angle most is about $90^{\circ}$.

\section{Reasonable well space for preventing pressure channeling}

In order to investigate the influence of well pattern and well space on productivity after fracturing in study area, using numerical simulation on low permeability reservoir in the presence of a high conductivity fracture, comparison with effect on productivity under different well space, so as to optimize the reasonable well space which can both guarantee the maximum productivity and prevent fracturing channeling.

\subsection{Basic parameters of model}

Combined with practical situation, 8 fracturing sections are chose to simulate two wells, and the horizontal section is $640 \mathrm{~m}$, and the distance between the two wells is $510 \mathrm{~m}$. Fractured section is an average of $80 \mathrm{~m}$, but fracture half-length is between $75 \mathrm{~m}, 105 \mathrm{~m}, 135 \mathrm{~m}$ and $165 \mathrm{~m}$. Fractures are not connected after fracturing and the unconnected fractures distance are $360 \mathrm{~m}, 300 \mathrm{~m}, 240 \mathrm{~m}$ and $180 \mathrm{~m}$. The assumed model is a homogeneous. The porosity is $10 \%$ and the permeability is $0.15 \mathrm{mD}$, and the vertical permeability is 0.5 times of the horizontal permeability. The rock compressibility coefficient is $11.55^{*} 10^{-4} \mathrm{MPa}^{-1}$; the viscosity of crude oil is $6.4 \mathrm{mPas}\left(64.7^{\circ} \mathrm{C}\right)$, and the density of crude oil is $0.866 \mathrm{~g} / \mathrm{cm} 3\left(64.7{ }^{\circ} \mathrm{C}\right)$.

4.2. Influence of well space on productivity

Through the numerical simulation, we can see the influence of well space on the productivity, as shown in figure 1 . The cumulative liquid production increases slowly when the fracture half-length is between $45 \mathrm{~m}$ and $105 \mathrm{~m}$. Cumulative liquid production increases significantly when the fracture half-length is between $135 \mathrm{~m}$ and $165 \mathrm{~m}$. Through the numerical simulation of daily oil production in eight fractured fracture with different fractures half-length under no fracturing channeling, it shows that large increase in production when fracture half-length increase from $45 \mathrm{~m}$ to $75 \mathrm{~m}$, increase in production slightly from $75 \mathrm{~m}$ to $135 \mathrm{~m}$, increase in production from $135 \mathrm{~m}$ to $165 \mathrm{~m}$ is very small. The optimum value of the fracture half-length is $105-135 \mathrm{~m}$. 


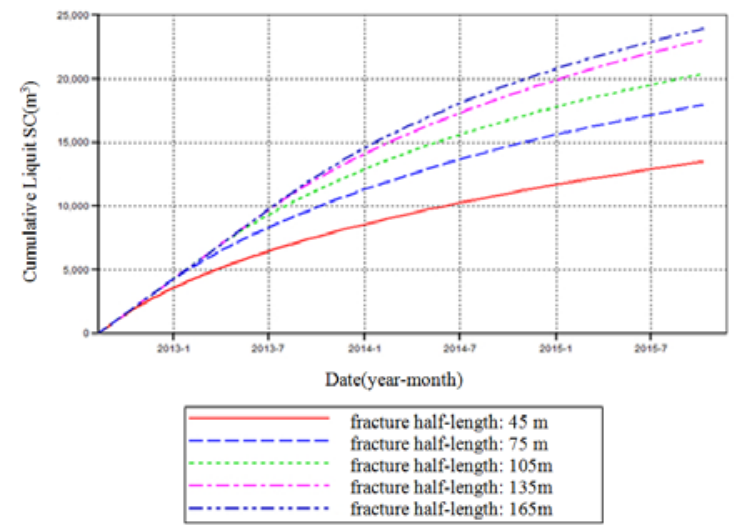

Figure 1. Variation curves of cumulative liquid production of fracture

So, for the low permeability reservoir, with the fractures half-length increasing, liquid production does, under the other conditions are the same, choosing a relatively optimal the fracture half-length; the best value of the fracture half-length is $105-135 \mathrm{~m}$; if the sections are easy to fracturing channeling, choosing the fracture half-length is $75 \mathrm{~m}$, the influence on productivity is not particularly obvious.

\subsection{The influence of the number of fracturing section on the productivity}

In above example, with the number of fracturing sections from 7 to 8 , the increase on productivity is decreasing. This reason is the fractures space is not large enough. With the increase in the number of fractures, mutual interference among fractures will be serious. Due to the decrease on formation pressure is large, the production of each fracture decreases. Therefore, the optimal number of fractures is $6 \sim 7$ in above condition.

\subsection{The impact of fractures space on productivity}

Based on the different fractures space and different fracture arrangement styles, the change of capacity is analysed. Five fracturing sections under different fracture arrangement styles lead to the change of productivity. There are three kinds of situations. A. fractures uniform distribution; B. fractures end space is small, middle space is large; C. fractures end space is large, middle space is small. The above summary shows that the distribution of fractures have a significant impact on productivity, the cumulative liquid production and daily oil production have different changes. In the case of the uniform distribution of the fractures, liquid production and the daily oil production are all smaller than that of the non-uniform distribution (the difference between the fractures space). Therefore, non-uniform distribution of artificial fractures space is conducive to improve productivity.

Comprehensive analysis the impact of the number of fractures on the productivity shown, the numbers of fracturing sections and fractures half-length have effect on productivity after fracturing. Comparing with the effect of fractures half-length and the number of the fractured sections on the productivity, they have same great effect on the productivity. To design and select $85 \mathrm{~m}$ for the optimal fracture space, the minimum value of fractures half-length is $135 \mathrm{~m}$. In the special well sections or well sections are easy to fracturing channeling, choosing smaller fractures half-length $(105 \mathrm{~m})$ has no evident effect on productivity but effectively preventing fracturing channeling.

\section{Preventing fracturing channeling deployment scheme of well pattern and well space}

Based on the above analysis, on the basis of preventing fracturing channeling have been determined, trying to follow the following requirements. First, horizontal sections of horizontal wells at maximum horizontal principal stress direction should dislocate deployment; second, avoiding or clearing reservoir geological characteristics of inter-well higher fracturing channeling rate, preparing for fracturing construction to take corresponding measures; third, considering comprehensively the late complement formation energy, arrangement well scheme of preventing fracturing channeling; fourth, specific treatment for specific well area and specific geological feature of the reservoir; fifth, ensuring maximum capacity. The recommended well pattern and well space deployment scheme of fracturing channeling is as followed. 


\subsection{Horizontal well staggered determinant well pattern}

Based on the analysis of the oilfield data and numerical simulation research, with taking into account the capacity of the study area from the overall fracturing, it is not the best choice to increase well space. The deployment of the new district or the adjustment well can prevent the fracturing channeling through the dislocation. The recommended well pattern is shown in Figure 2

1. Oilfield statistics show that horizontal section of horizontal well in the direction of the maximum horizontal principal stress can effectively avoid the interwell fracturing channeling. Water injection wells initial use for oil production will not cause fracturing channeling in Figure 2 (a).

2. From the degree of recovery, degree of recovery of horizontal well pattern is much better than vertical wells. The degree of recovery of stagger determinant well pattern of horizontal well injection and production is the highest; the vertical well injection, horizontal and vertical well production comes second; the determinant well pattern of the vertical injection and production is the lowest. Obviously, compared with the all vertical well pattern, the all horizontal well pattern has the very big development dominance.

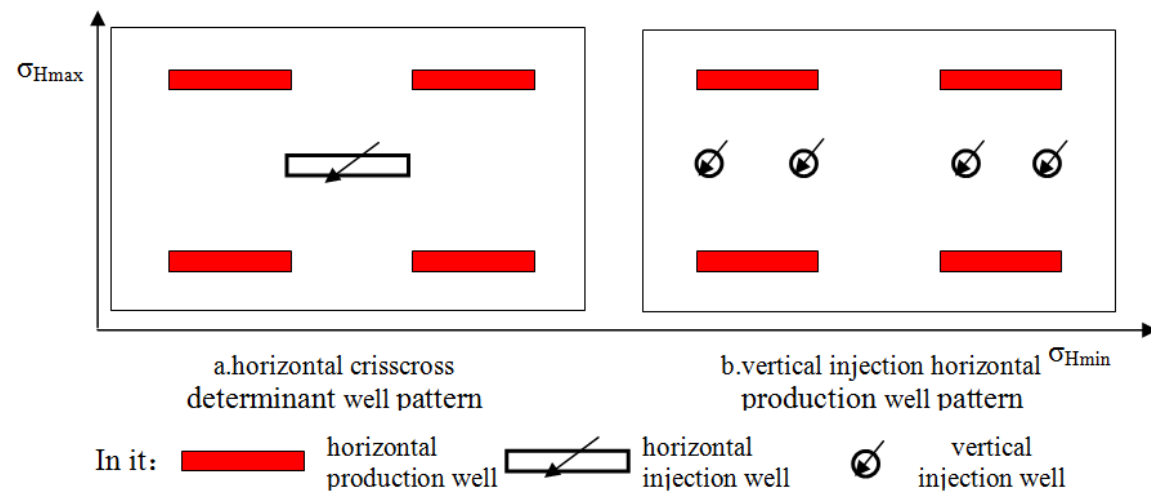

Figure 2. Schematic of two kinds of well pattern deployment

\subsection{Determinant well pattern of the vertical well injection and horizontal well production}

The determinant well pattern of the vertical well injection and horizontal well production is shown in Figure 2(b). The distribution of faults, fracture zone and fractures between two horizontal sections is very complex. Therefore, accurate quantitative description is very difficult. When the reservoir must be added energy, vertical well injection can greatly reduce the probability of geological factors connected of fracturing channeling conditions between borehole and interwell.

5.3. Horizontal well bore parallel fracture deployment

According to the theory of horizontal well fracturing, when the horizontal section perpendicular to fractures, through combining with the perforating mode, the artificial fractures which are vertical wellbore can be produced when artificial fracturing, which can increase the capacity. In some cases, considering wellbore stability and geological factors, the horizontal well bore parallel fracture deployment, artificial fracturing produced a hydraulic fracture which is parallel to maximum principal stresses. Moreover, it is developed on the top of the shaft and the bottom is not developed.

To sum up, for the case of Honghe oilfield, it is recommended along the maximum principal stress direction dislocation deployment; vertical well and horizontal well mixed deployment; integral fracture zone infill adjustment; increase the parallel or small angle horizontal test wells to try increasing the capacity of the vertical permeability.

\section{Conclusion}

1. The determinant well pattern has been deployed in the study area, and the horizontal sections are perpendicular to the maximum horizontal principal stress. The ground stress controls the extension direction of fractured fractures. fault, fracture zone and fracture form the inter-well high permeability zone, which distribution determines the fracture half-length. The narrower and longer and more concentrated high permeability zone is, the higher fracturing channeling rate become, on the contrary, the lower. 
2. staggered determinant well pattern of horizontal wells, increasing the number of fracturing sections and the well space, reducing the scale of the fracturing can not only to reduce the fracturing channeling rate effectively, but also to ensure that the productivity requirements.

3. The angle of the horizontal section of the horizontal well and the maximum horizontal principal stress varies from 90 to 0 degrees. The fracture half-length decreases, the possibility of fracturing channeling of adjacent well in the horizontal section vertical direction is reduced. The individual wells with angle of 0 degree obtain high productivity in study area.

4. Determining the location of high permeability zone and its development scale is an important basis for well completion and fracturing project which prevent fracturing channelling, and it is also the necessary condition to treat fracturing channeling which has happened.

\section{Acknowledgments}

In this paper, this research was sponsored by the Natural Science Foundation of Shaanxi Province (Project No. 2013JM5006) and North China Company, SINOPEC, Study on the Comprehensive Control Technology of Horizontal Well Fracturing Channeling in Honghe oilfield(Project No. 34550000-13-ZC0609-0010).

\section{References}

[1] Zhang Juan, Development of fractures of Chang 8 formation in Zhenjing and its relationship with the exploitation [D], Chengdu University of Technology, 2010.

[2] Lin Yanbing, Hu Aiguo, Chen Fuhu, Xiong Pei, Yao Changyu, et al Horizontal well fracturing channeling cause analysis and channeling prevention countermeasures in Honghe oilfield[J], Reservoir Evaluation and Development, 2013, 3(4) 56-61.

[3] Zhang Yang, Yan Tie, Study on fracture initiation and extension mechanism of artificial fractures in fractured reservoirs [D], Northeast Petroleum University, 2012.

[4] Jin Yan ,Chen Mian, et al. Hydraulic fracturing initiation pressure models for directional wells in naturally fractured formation[J], Acta Petrolei Sinica, 2006, 27(5) 124-126

[5] M.W. Osborne, Harry O McLeod. Jr. and Herbert D. Schroeder, Conoco, Inc. The Analysis And Control Of Hydraulic Fracturing Problems[J]. Denver, Colorado, Low Permeability SympoSium, 1981, 365-366. 